\title{
Clinical Innovation: ------Activation Beads In Orthodontics
}

\author{
Dr. Suchita Daokar ${ }^{1}$, Dr. Handa Amit ${ }^{2}$, Dr. Vishal Patni ${ }^{3}$, Dr. Charushila \\ Chaudhri $^{4,}$ Dr. Suhas Biday ${ }^{5}$
}

\begin{abstract}
Many appliances in orthodontics such as fixed functional appliances, open coil springs, etc. depend upon some or the other means of activating the appliances. These activations are usually carried out through the way of activation beads been supplied by the manufacturers. The disadvantage of these beads includes its cost and its limited availability. Thus a new method of activating the fixed functional appliances is been described in here. Also, this method has its applicability for activation of other orthodontic appliances requiring activations.
\end{abstract}

\section{Introduction:-}

For effective and efficient results the orthodontic appliances should be activated in a proper manner and required direction. Various appliances depends upon the activation beads for the activation or for further activation such as open coil springs, fixed functional appliances, molar distalizers, etc.

In $70 \%$ of growing skeletal class II malocclusion cases, the cause is mandibular retrognathism ${ }^{1}$.

For years orthodontists have searched on functional appliances for correction of skeletal discrepancy.

Removable functional appliances have the disadvantages such as they are bulky, very large, restrict tongue movements, speech problems, exert pressure on the mucosa, lack tactile sensibility and most importantly depend upon patient`s compliance.

Fixed functional appliances have the advantage that they do not depend upon patient compliance and act for 24 hours.

FORSUS ${ }^{\mathrm{TM}}$ is gaining ground as the commonest fixed functional appliance used. Manufactures provides Forsus in 4 sizes and comprises of push rod, compression spring assembly and L-pin. This appliance may have to be further activated with the help of a pair of metallic beads provided by the manufacturer ${ }^{2,3,4}$.

It has but come to notice that the provided beads sometimes are insufficient for reactivation as in cases of severe skeletal discrepancy, large overjets, etc. at the start of the treatment.The reactivation of Forsus in such cases becomes difficult. So a simple technique to reactivate the Forsus appliance is been described.

\section{Method:-}

A simple plastic ball pen refill (with lumen size $-0.5 \mathrm{~mm}$ greater than push rod diameter) was been selected (figure 1) and with the help of a digital vernier caliper, refill of $2 \mathrm{~mm}$ sizes was measured and then cut with a sharp instrument (figure 2).

These plastic beads were inserted onto the push rod of the Forsus appliance and were used as the activation beads; thus the appliance got further activated by $2 \mathrm{~mm}$ (figures $3,4,5$ ).

\section{Other Advantages:-}

- These plastic beads can be used with any other appliances needing activations. Thus appliances depending for further activation can be helped from such beads.

- Also these beads can be helpful for activation of various coil springs, such as activation of open coils over archwires for opening of spaces (figure 6).

- Cost effective activation of various appliances.

- Easily availability of the refills.

- The amount of activation required can be achieved by cutting the appropriate length of the refill.

- Easy to prepare and insert. 


\section{Figures:-}

Figure no 1:- Plastic Ball Pen Refill.

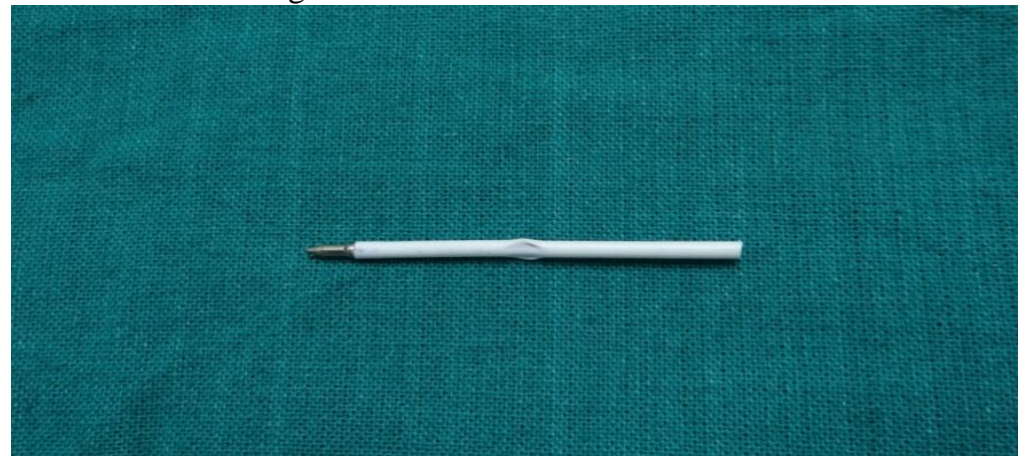

Figure no 2:- Refill was been cut in $2 \mathrm{~mm}$ sizes.

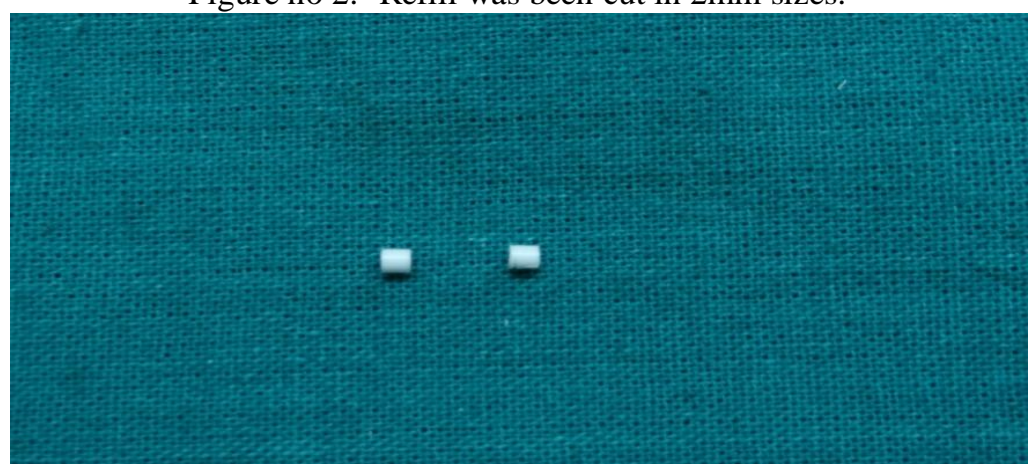

Figure no 3:-Frontal view of patient showing Forsus appliance and Plastic activation beads $(2 \mathrm{~mm})$.

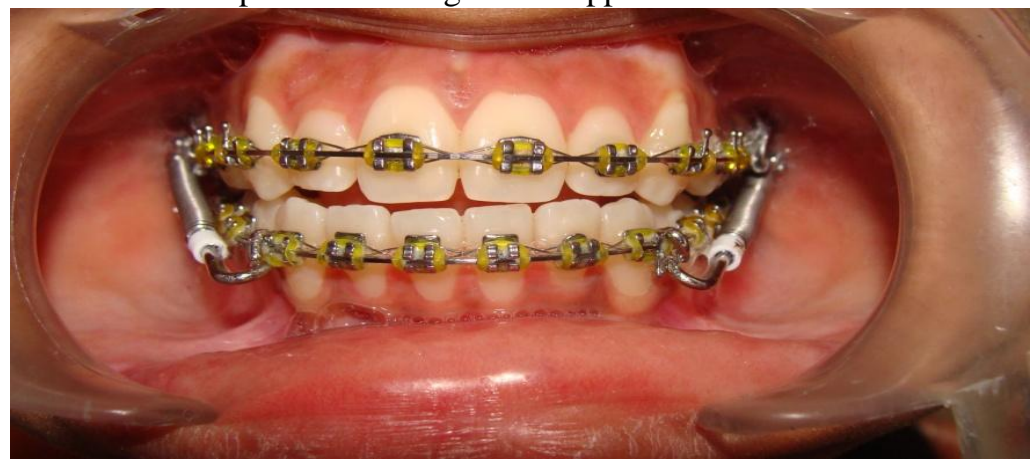

Figure no 4:-Left side view of patient showing Forsus appliance and Plastic activation bead $(2 \mathrm{~mm})$.

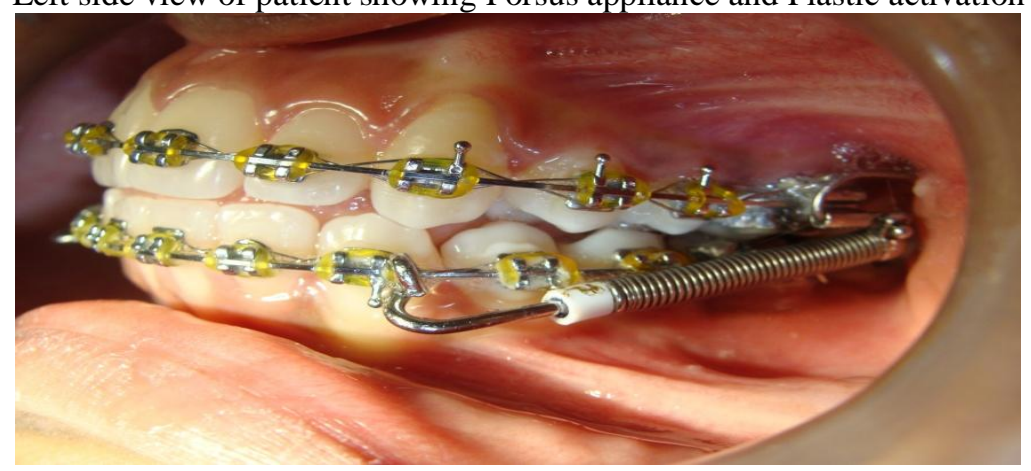


Figure no 5:-Right side view of patient showing Forsus appliance and Plastic activation bead.

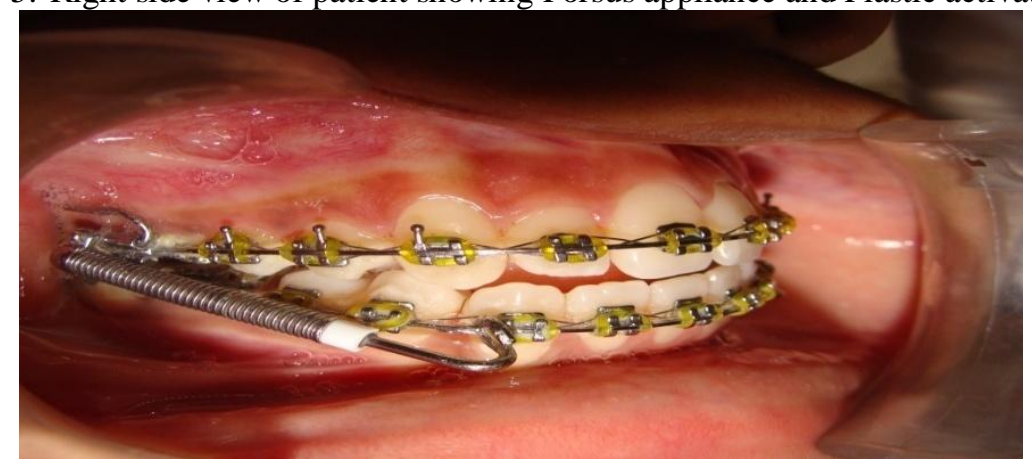

Figure no 6:-Activation of the open coil spring with the Plastic activation bead.

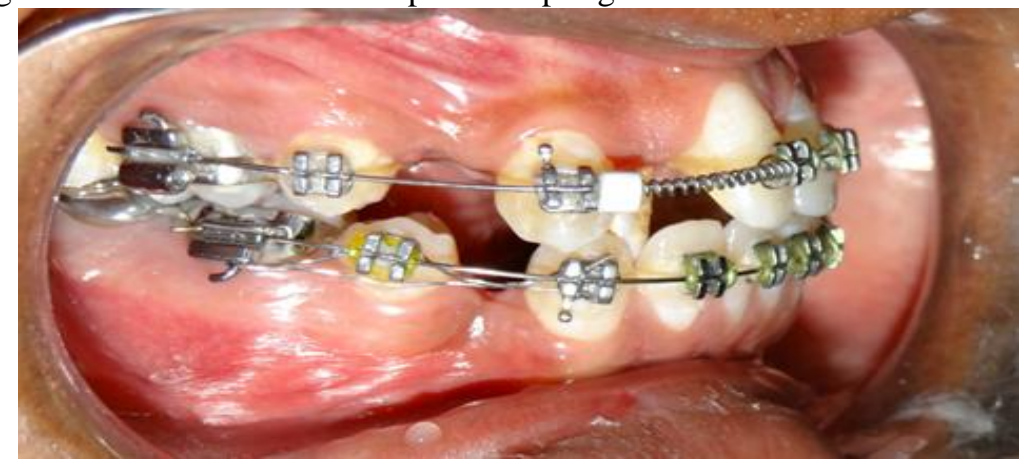

\section{References:-}

[1]. McNamara JA, Jr. Components of class II malocclusion in children 8-10 years of age. Angle orthod 1981;51:177-202.

[2]. A Korrodi Ritto, Fixed functional appliances-A classification (updated) The orthodontic cyber journal. www.oci.com / june 01/ Rittoffa.Htm

[3]. Vogt W. The Forsus fatigue resistant device. JCO 2006 Jun 40(6);368-77.

[4]. www.3mUnitek.com

[5]. William Proffit. Contemporary orthodontics, 4 edition.

Author's information:-

1) Dr. Suchita S. Daokar, Professor and P.G. Guide, Department of Orthodontics and Dentofacial Orthopaedics, C.S.M.S.S. Dental College and hospital, Kanchanwadi, Aurangabad, Maharashtra, India.

2) Dr. Handa Amit Satish, Post-Graduate student, Department of Orthodontics and Dentofacial Orthopaedics, C.S.M.S.S. Dental College and hospital, Kanchanwadi, Aurangabad, Maharashtra, India.

3) Dr. Vishal Patni, M.D.S. Orthodontics and Dentofacial Orthopaedics, Aurangabad, Maharashtra, India.

4) Dr. Charushila Chaudhri, Post-Graduate student, Department of Orthodontics and Dentofacial Orthopaedics, C.S.M.S.S. Dental College and hospital, Kanchanwadi, Aurangabad, Maharashtra, India.

5) Dr. Suhas Biday, Post-Graduate student, Department of Orthodontics and Dentofacial Orthopaedics, C.S.M.S.S. Dental College and hospital, Kanchanwadi, Aurangabad, Maharashtra, India. 